\title{
Influence of Drought Mitigation Strategies on Food Security: A Case of Laikipia East, Laikipia County, Kenya
}

\author{
George O. Muhua, \\ John K. Waweru, \\ University of Nairobi, Kenya
}

doi: 10.19044/esj.2017.v13n18p579 URL:http://dx.doi.org/10.19044/esj.2017.v13n18p579

\begin{abstract}
Achieving food security in the Kenyan ASALs during droughts is a constant challenge. Reactive approaches to drought-risk management have been ineffective and poorly coordinated leading to vulnerability of households to food insecurity despite adoption of Hyogo Framework of Action 2005-2015 (HFA). HFA recommends continuous systematic planning and management of drought risk, as it should be anticipated and planned for, in its manifest phases of normalcy, early stage, alert and emergency periods each with specific mitigation activities. The study with special reference to Laikipia East Sub-County revealed that majority of households were aware of drought mitigation strategies which influenced household food security but these were poorly coordinated, late, insufficient and lacked sufficient funding. The study also found out that household participation was low in implementation. The study recommends more capacity building on drought mitigation strategies, timely planning for drought to ensure coordinated response to drought especially in human and livestock relief projects. Finally the study recommends involvement of technical field officials and local leaders as they are better placed to identify working strategies and rightful targeting.
\end{abstract}

Keywords: Drought, Food insecurity, mitigation strategies.

\section{Introduction}

The Drought frequency, intensity and impacts of drought have been increasing especially in ASALs affecting natural resources and socioeconomic systems the consequences being loss of food crops, shortage of clean water, loss of grazing land and displacement of households (UNISDR, 2009). In Kenya drought is the most prevalent hazard that affects many especially in the vast Arid and Semi-Arid Lands and over the last 35 years at 
least nine severe droughts have taken place, affecting an increasing number of people (Government of Kenya, 2009).

The 1999/2001 and 2004/2006 affected 4.4 and 3.5 million people respectively, including those living outside the pastoralist areas (Schilderinck, 2009) with value of livestock that died in Kenya due to the 1999-2001 droughts estimated at US\$ 77.3 million, whereas the value of food aid distributed by the Kenyan government, the World Food Programme and other agencies during this same was US\$ 200 million (Aklilu and Wekesa, 2001). The 2006 drought hit 37 out 78 districts leaving a population of 3.5 million people in need of relief (Government of Kenya, 2009).

These challenges posed by drought led to Governments and states convening in 2005 Hyogo conference under UNISDR which bore Hyogo Framework of Action (HFA) 2005-2015 to encourage implementation of drought risk management programmes giving impetus to DRR National plans and strategies to limit drought risks. In India, the government devised medium and long term strategies to mitigate and overcome adverse effects of drought (Samra, 2004). In Uganda, National Disaster Risk Reduction and Management policy was reviewed to focus on comprehensive risk management (UNISDR, 2007). In Kenya, a National Disaster Management authority (NDMA) with the objective of laying a strong foundation towards sustenance of community resilience to disasters has been established which in effect has localized the HFA 2005-2015. Vision 2030 identifies high disaster zones in ASALs as strategic thrusts in which to reduce losses from drought through Disaster Risk Reduction (DRR) activities.

Sen (1981) identifies drought as a factor that can deprive large sections of population of their entitlement to adequate food. Turnbull (2010) highlights the need for drought early warning systems to monitor the cumulative impact of food shocks on livelihoods, as well as investment in long-term measures to strengthen people's ability to cope with drought shocks. Particular attention should be paid to pastoral areas, due to the extent of historical marginalization and weak disaster response systems.

FAO et al, (2013), defines food security as a situation that exists when all people, at all times have physical, social and economic access to sufficient, safe and nutritious food that meets their dietary needs and food preferences for active and healthy life. Food security is a challenge with 1.02 billion people being food insecure and among the most affected areas of the world are the ASALs which make up to $40 \%$ of earth's surface (Population Reference Bureau, 2010 and Government of Kenya, 2009). These ASALs are home to the world poorest with lowest development indicators and high incidences of food insecurity exacerbated by frequent droughts. Less than $50 \%$ of Sub-Saharan African countries have levels of malnutrition under $30 \%$ and only three of them are under 10\% (Government of Kenya, 2009). 
Laikipia East is ASAL and in every four to five years there is a major drought which adversely affects people's livelihoods (Republic of Kenya, 2008) with adverse effects on food security requiring external interventions.

\section{Statement of the problem}

In Kenya, about 10 million people live in drought prone ASALs which covers about $80 \%$ of Kenya's land and $51 \%$ of Kenya population lack access to adequate food (Government of Kenya, 2009). By the end of 2013, 850,000 people were facing food insecurity and in January 2014, almost all livelihood zones in Laikipia East were worsening (NDMA, 2014). Laikipia East is prone to climatic shocks and in every four to five years, major droughts have occured with devastating effects on people's livelihoods (Republic of Kenya, 2008).

While so much has been done on drought response (population affected and relief), very little on how households become aware, adopt and implement drought mitigation strategies and their influence on food insecurity. Ouma et al (2012) assessed post-drought strategies in Northern Turkana among the Turkana while Zwaagstra et al (2010) assessed the response to 2008-2009 drought in Kenya. Further, while there is research on food security in various other ASALs areas in Kenya, none had focused on how drought mitigation influenced household food insecurity in Laikipia East, Laikipia County, Kenya. The study sought to link the extent to which drought mitigation strategies influenced household food security in Laikipia East.

\section{Objectives}

The major objective of the study was to establish the influence of drought mitigation strategies on food security in Laikipia East, Laikipia County, Kenya. The specific objectives of the study were;

1. To establish how drought preparedness influence household food security in Laikipia East, Laikipia County, Kenya.

2. To find out the extent to which drought response activities influence household food security in Laikipia East, Laikipia County, Kenya.

3. To determine the influence of reconstruction activities after drought on household food security in Laikipia east, Laikipia County, Kenya.

\section{Literature review}

\section{Drought mitigation strategies and food security}

FAO et al (2013) identifies drought as the most common cause of severe food shortages with effects of lower yields from crops and livestock, livestock deaths, plant and animal diseases and land degradation. It negatively affects food security, especially in developing countries and its 
impacts are among the most common events and processes in Africa accounting to $80 \%$ of loss of life and $70 \%$ of economic loses of natural resources (UNDP, 2011). For pastoralists and agro-pastoralists households, whose livelihoods and food security depend on livestock and crops, drought conditions can cause malnutrition or disease in livestock because of insufficient fodder and deterioration in pastoral lands (UNISDR, 2009).

Drought periods can be anticipated and managed, failure to which, there are major socio-economic consequences especially in developing countries where an outcome of drought is the risk of extreme food insecurity (UNISDR, 2007). The adverse impacts of hazards often cannot be prevented fully, but their scale or severity can be substantially lessened by various strategies and actions. Despite several strategies to combat the effects of drought on food production, deficits continue to occur (Omiti and Nyanaba, 2007).

\section{Drought Preparedness and Food Security}

Drought preparedness is a set of established policies, plans and activities undertaken before an apparent threat of drought to enhance coping by forecasting approaching dangers and ensure coordinated and effective responses to drought (UNISDR, 2007; 2009). It includes capacity building, early warning systems and contingency planning for effective response and recovery (Concern, 2005). As with other natural hazards, preparedness is vital towards reducing the impacts of drought on food security (Wilhite, et al, 2005).

Resilience to drought can be enhanced through the creation of early warning systems (EWS) for improved coordination of drought mitigation activities between stakeholders (Wilhite, et al, 2005). EWS provides timely drought status information used in decision making and response planning at various levels in regard to the stage of drought risk of food insecurity and recommendations for necessary action (Hayes, Svoboda, Knutson, \& Wilhite, 2004). The main aim of the EWS is to provide a timely situational analysis on the country's vulnerability to drought, which informs government decisions regarding food security and the formal declaration of drought.

Capacity building strengthens people's ability and capability to determine their own values and priorities, organize themselves to act on these priorities that calls for training of local leadership so that people can fully be involved in drought mitigation. During capacity development organizations and society systematically stimulate and develop their capacities over time to achieve social and economic goals, including improvement of knowledge, skills, systems, and institutions to cope with drought (UNISDR, 2009). 
Drought contingency planning emphasizes in formalizing and enforcing the process from clarity in the roles of different individuals, communities and institutions in managing drought risks. To make it through a bad drought, with the least damage financially, emotionally, and to the animals and pasture, a drought plan is required to minimizes damage when drought eventually strikes hence reducing the risk and cost associated with a drought (Rayburn, 2007).

\section{Drought Response Activities and Food Security}

Drought response is the provision of emergency services and public assistance during or immediately after a drought in order to save lives, to reduce adverse health impacts, ensure public safety and meet the basic subsistence needs of the people affected. It is predominantly focused on immediate and short-term needs. Early response enables affected households to cope with drought and to continue developing while late response includes provision of food aid to the affected households both for human consumption and livestock. For early response resources need to be pre-positioned in locations where they are likely to be needed, however this is rarely the case (Zwaagstra, et al 2010). According to UNISDR (2009), response efforts can create dependency and other new vulnerabilities and may not reduce underlying drought risk factors and vulnerabilities, making the same affected individuals to experience similar or more extreme conditions the next time a drought occur. Further, many studies have shown that investing in natural hazards preparedness and vulnerability reduction strategies is more costeffective than relying solely on response activities. Responses are generally progressive as drought conditions persist, and are dependent on the severity of drought (Barton \& Morton, 2001).

Human and livestock relief involves activities that are carried out during and immediately after drought has occurred in order to save lives, reduce health impacts, ensure public safety and meet the basic subsistence needs of the affected households. Food aid can save lives particularly when general distribution rations are adequate in both nutritional quality and quantity (Duffield, 2004). Food distribution should start early, last long enough, and be reliable and plentiful enough to serve as an income transfer during food crisis (DFID, 2006; Jere, 2007). Such efforts in Kenya include hay and supplementary feeds distributed to all arid and semi arid areas in 2009 at two intervals which included water trucking, hay mash, molasses and survival cubes (Zwaagstra et al, 2010).

Destocking is resisted by pastoralists because during drought few animals to supply milk or wealth creating capability and therefore perceived to increase poverty and risks for survival. Alternatively, destocking can create marketing channels for weaker animals, thereby enabling herders to 
keep stronger animals in their herd, preserving a key household capital asset for post-drought recovery. Despite its obvious benefits commercial destocking is the least cost-effective due to long distances to markets, poor timing of interventions and lack of economies of scale all play important roles in making this kind of de-stocking unviable.

Cash-based responses to drought are credible and preferred alternatives to in-kind assistance especially where commodities are available and affordable. Increasingly, agencies and donors are taking a 'cash-first' response to livelihoods and food crises because cash has a wide variety of applications in drought response (Harvey and Bailey, 2011). Cash transfers are most commonly used to address food insecurity and nutrition in emergencies, often as an alternative to food aid (Harvey and Bailey, 2011).

Cash, when provided early enough, can reduce the need for more costly interventions later (Pantuliano and Wekesa, 2008) as it is easy to carry and where food is available in markets allows the affected households to continue moving with their herds and protects the health and nutrition of pastoral families (Levine \& Crosskey, 2006).

\section{Reconstruction Activities and Food Security}

Reconstruction involves decisions and actions taken after a drought with a view to restoring or improving the pre-drought living conditions of the drought stricken community, while encouraging and facilitating necessary adjustments to reduce drought risk (UNISDR 2009; Bazza 2002). Reconstruction activities should take place at the end of the drought cycle, as normalcy returns and should aim at restoring people either to their normal livelihoods or to improved and less vulnerable livelihoods Heffernan et al (2004). Reconstruction is a rebuilding measure which focuses on human and material resource development, coordinated effort towards independence, sustainability and empowerment. These activities therefore results to a return to the same degree of food security experienced before the drought crisis, or to an improved capacity to cope.

Restocking involves the provision of livestock to households, who have lost their herds as a result of drought in the post drought period. It is increasingly viewed as the primary method of rehabilitating the small-scale pastoral sector after drought by lifting the impoverished into the social and economic fabric of pastoralism (Heffernan, 2001). Restocking programmes have been widely used in Africa as a means to enable pastoralists to resume their livelihoods. Heffernan (2001) however observes that although restocking projects are viewed as a method of supporting households' immediate nutritional needs and livelihoods in the long-run and therefore often justified as a means of improving household food security, little evidence exists that programmes are able to fulfill these goals. 
Another reconstruction strategy is provision of farm inputs during and after droughts to re-establish a 'self-help' mode within communities affected. Once households have seeds and basic tools, they can start the process of producing their own food and making money from selling crops, and thereby reduce their dependence on external sources for their livelihoods. The distribution of free or cheap farm inputs is being assigned increasing attention and is becoming a common intervention in drought situations (FAO et al, 2013). Nyamwange (1995) observes that. the major problem encountered in distribution of farm inputs is the difficulty of getting seeds, fertilizer and tools on time because supplies may be limited due to drought. Incentives may exist for farmers to sell seeds or fertilizer intended for their use. In addition, such programmes can depress the demand for inputs from the private sector dealers when distributed through government agencies that exclude private sector participation and poor targeting can hamper efficiency.

Lastly, the destroyed assets should be restored and improved under "build back better" to reduce future vulnerabilities to drought after drought is brought under control. It involves medium term interventions such as provision of social services, road clearing, rehabilitation of water points and systems to revitalize drought affected areas.

\section{Study Area and Methods of data Collection}

This study was carried out in the semiarid areas of Laikipia East, Laikipia County in Kenya. Data was collected from households in Muhonia, Njoguini, Kariguini, Wamura and Ethi areas which practice rain fed agropastoralism activities to produce food. The area lies in the leeward side of Mt. Kenya and rainfall is therefore generally low. The area in the recent past suffered from frequent drought estimated to occur after every three to four years having serious consequences on food production. The main methods of data collection used were questionnaires and interview schedules. A total of 242 household heads randomly sampled were interviewed, 5 chiefs and three Sub-County departmental officials were interviewed. Relevant literature was obtained to supplement information collected from the field. Descriptive research design was used.

\section{Results and discussions \\ Effects of drought on food sources}

According to Ngaira (2005) the effects of drought are mainly seen in poor production in both crops and livestock culminating into food insecurity. In the area of study, households got their food from a mix of sources, and during droughts availability and access were adversely affected with only $14 \%$ eating a balanced diet always during droughts. The study also 
established that a massive $97 \%$ worried for food and water to get them through the drought period pointing to vulnerability of households to food insecurity. Indeed, only 6.4 of households stated to have enough kind of food and clean water the rest attributing their situation loss of food crops, water points, livestock and hikes in food prices as a consequence of drought. Huho and Mugalavai (2010) agree with these findings, that families in times of drought operate under conditions where most of necessary production assets have been destroyed which affect food production and hence threaten food security.

\section{Drought preparedness}

Drought preparedness involves activities taken during the normal and alert phases of drought to increase the ability of households to cope with drought when it finally strikes. The study found out that majority all the households were aware of at least one drought mitigation strategy with media found to have played an important role in preparing for drought with $48.9 \%$ of the households by disseminating early warning information.

Despite presence of extension agents in the grassroots, many did not consider them as a source of forecast information. Households applied a mix of responses but $9.4 \%$ indicated to have taken no action leaving them susceptible to effects of drought. On capacity development, despite capacity development being rated highly as important by those trained, there was a big gap on knowledge dissemination and sharing as only $50.7 \%$ had been trained which indicates that many households lacked knowledge on drought mitigation and therefore ability to adequately prepare for droughts. Equally, planning was largely unpopular with only $24.7 \%$ having elaborate contingency plans which they described as very effective by giving options in times of drought. This would leave the rest of households with limited options in times of drought therefore increased drought risk of food insecurity.

\section{Drought Response}

Response to drought is the most popular drought intervention strategy during the emergency. The second objective of the study sought to establish the extent to which response activities influence food security. The results indicated that relief assistance was substantially popular with $74.2 \%$ having received assistance in varied forms leaving a quarter of the households. Barret and Maxwell (2005) points out the risk of deserving households missing on relief assistance due to problems of targeting. Among the recipients, majority felt that it was not sufficient to provide household food security. Similarly, Roy and Hirway (2007) found out that majority of households were unsatisfied with relief work during drought. 
Reduction of livestock herds was also studied and was carried out through slaughtering of weak animals, herd splitting and migration and majority opted to sell their stock before they could lose them and use the proceeds to purchase food from the market. Destocking was therefore highly rated as a mitigation strategy. Destocking is the most useful intervention to drought (Abebe, 2008) and the most successful due to strong community interest and involvement (ALNAP, 2011). Zwaagstra et al (2010) however found out that destocking interventions were late and poorly coordinated and therefore rarely had significant impact. Respondents in this study recalled how they had lost their livestock in a government uptake programme while awaiting officials from Kenya meat commission after travelling for long distances which was eventually called off anyway. Lastly, the study sought to know the influence of cash transfer on food security. Not only was it found to be unpopular amongst service agents, only 34\% households had benefited, it was also regarded insufficient to provided food security in times of drought. Cash transfer is highly preferred by its recipients of assistance during droughts as it gives them the choice of participating in the market and purchasing without really affecting the local economic systems (O'Donnell, 2007).

\section{Reconstruction after drought}

The study examined the influence of reconstruction activities in the aftermath of drought. These are restocking, distribution of farm inputs and infrastructure development. Restocking was found to have been used by majority of households as they considered it important strategy of reducing vulnerability to food insecurity. According Heffernan (2001), restocking pastoralists is a successful means of rehabilitation as it has the greatest impacts on pastoral communities. Zwaagstra (2010) contends that restocking programmes have involved very few pastoralists as they are expensive to implement. The study also found out that most external agencies did not implement such programmes as they are associated with high logistical costs and poor long term effects and households had to use their already depleted resources to restock. Buying stock from the market $45 \%$ and breeding from household stock $39 \%$ were the common methods of restocking which faced challenges of few animals in the market and within the household for effective restocking. Its feasibility can also be questioned in the face of frequent recurring droughts as it is considered as a temporary respite as restocked herds face the risk of being lost in future droughts (Heffernan, 2001). ). This study found out that households did not consider restocking to have immediate major influence on their food security as it takes time for them to replenish and be productive. 
Among the agro-pastoralists, it is important to provide early maturing drought resistant certified seeds, subsidized fertilizers and farm implements once the drought is over to reestablish food banks and pasture land for the livestock. There is need to plan for storage of both food yields and fodder for the animals once they are harvested as often households are forced to sell their produce after bumper harvests or end up losing it altogether, a prerequisite for food insecurity. This study found out that despite the important role associated with distribution of farm inputs, households were left on their own to source for farm inputs with $69.4 \%$ to purchase from the market or use seeds from previous harvests. The distribution was criticized being influenced by favoritism and political manipulations to the exclusion of deserving cases. Officials also felt left out and sometimes seeds distributed were unsuitable for local environment. These findings are in line with Rohrbach et al 2005 that not all households benefit from these programmes, and for the few that benefit, farm inputs are rarely put into their desired use. Generally, distribution of farm inputs was regarded to provide household food security $84.5 \%$, after droughts but not to a level where all households felt cushioned against drought risk of food insecurity.

On infrastructure rehabilitation, construction and revival of water points were popular activities while few households participated in roads repair. These had considerable influence on household food security as water could readily be available and mobility easier with $97.3 \%$ favorably viewing them to impact food security. However, felt the need to expand these activities to improve on food security like construction of cereal banks.

\section{Conclusion}

Droughts have increased in frequency and severity increasingly affecting more people in terms of food and water shortage. It is therefore important for concerted approaches to drought mitigation when droughts finally strike to increase household capacities and resilience to food insecurity. The findings established that there is a drought increased household vulnerability to food insecurity due to reduced availability and access to quality and sufficient food and water. This led to the conclusion that drought mitigation strategies would therefore reduce drought risk of food insecurity. The study established that, despite preparedness strategies being popular, implementation/uptake at the household level had gaps of for example poor response to EWS, limited training and poor contingency plans. Equally, response activities were found to have flaws right from timeliness, targeting, implementation, coordination and sufficiency. Lastly, the study established that despite reconstruction activities being considered important by households, limited financial allocations were made to implement and run these activities. Most households were left on their own 
to use their already depleted resources for recovery. Participation on these activities was also found to be low. As such, drought mitigation strategies in Laikipia East were not sufficient to cushion all households from drought food insecurity.

\section{References:}

1. Abebe, D., Cullis, A., Aklilu Y., Mekonnen, G. \& Ghebrechirstos, Y. (2008). Impact of a commercial destocking relief intervention in Moyale District: Southern Ethiopia. Oxford: Blackwell publishers.

2. Aklilu, Y. \& Wekesa, M. (2001). Livestock and Livelihoods in Emergencies: Lessons Learnt from the 1999-2001 Emergency Response in the Pastoral Sector in Kenya, OAU-IBAR, Nairobi: Kenya.

3. ALNAP. (2011). ALNAP Lesson Paper: Humanitarian action in drought-related emergencies. ALNAP

4. Barrett, C.B. \& Maxwell, D.G. (2005). Food aid after fifty years: Recasting its role. Routledge, Canada and USA.

5. Barton D. \& Morton J. (2001). Livestock Marketing and Drought Mitigation in Northern Kenya, Drought, Planning and Pastoralists: Experiences from Northern Kenya and Elsewhere. (J. Morton, Ed.)., Chatham: NRI.

6. Bazza, M. (2002). Water Resources Planning and Management for Drought Mitigation: Prepared for FAO Regional Workshop on Capacity Building on Drought Mitigation in the Near East Rabat, Morocco. 1-5 November 2002. Retrieved on May 29, 2013 from ftp://ftp.fao.org/docrep/fao/meeting/010/af985e/af985e00.pdf

7. Concern. (2005). Approaches to Disaster Risk Reduction. UK: Concern Emergency Unit

8. DFID. (2006). Ethiopia's Productive Safety Net Programme (PSNP): Trends in transfers within targeted households. (S. Devereux, R. Sabates-Wheeler, M. Tefera \& H Taye, Eds.). Addis Ababa: IDS and Indak

9. Duffield, A. (2004). Review of the Published Literature for the Impact and Cost-effectiveness of Six Nutrition Related Emergency Interventions. Report prepared by the ENN.

10. FAO, IFAD and WFP. ( 2013). The State of Food Insecurity in the World 2013: The multiple dimensions of food security. Rome: FAO.

11. Government of Kenya, Ministry of State for Special Programmes, Office of the president. (2009). National policy for disaster management in Kenya. Nairoi: Government Press. 
12. Harvey, P. \& Bailey, S. (2011). Good Practice Review 11: Cash transfer programming in emergencies. London, UK: Humanitarian Practice Network (HPN).

13. Hayes, M.J., Svoboda, M.D., Knutson, C.L. \& Wilhite, D.A. (2004). Estimating the Economic Impacts of Drought: Proceedings of _4th Conference on Applied Climatology January, 2004.

14. Heffernan, C., Nielsen, L., \& Misturelli, F. (2004). Restocking Pastoralists: A manual of best practice and decision support tools. London: Intermediate Technology Development Group.

15. Huho, J.M. \& Mugalavai E.M. (2010). The effects of Drought on Food security in Kenya, Vol no. 2. Illnois. Common ground publishing LLC

16. Jere, P. (2007). The Impact of Food Aid on Food Markets and Food Insecurity in Malawi: A case study, Regional Network for Health Equity in Southern Africa. EQUINET discussion paper 45.

17. Levine, S. \& Crosskey, A. (2006). Can Pastoralism be brought back to life? Towards a safety net and a way forward for North East Turkana. Oxfam GB

18. NDMA, Laikipia County, (January, 2014), Drought monitoring and early warning bulletin, NDMA.

19. Ngaira, J.K.W. (2005) Hydrometeological disatsters and their impact on development: The Kenya experience. Maseno Journal of education, arts and sciences. Vol 5 no. 1.

20. Nyamwange M. (1995). Famine mitigation in Kenya: Some Practices, Impact and Lessons. East Stroudsburg: Middle States Geographer.

21. O’Donnell, M. (2007). Cash based livelihood recovery programme, Isiolo District,Kenya-project evaluation. Save the Children Canada.

22. Omiti, J. \& Nyanaba, t. (2007). Using Social Protection Policies to Reduce Vulnerability and Promote Economic Growth in Kenya: A Background Paper, Nairobi: KI PPRA.

23. Ouma, C., Obando, J. \& Koech, M. (2012). Post Drought recovery strategies among the Turkana pastoralists in Northern Kenya. Scholarly Journals of Biotechnology Vol. 1(5), pp. 90-100. Retrieved August 16, 2013, from http:// www.scholarly-journals.com/SJB

24. Pantuliano, S. \& Wekesa, M. (2008). Improving Drought Response in Pastoral Areas of Ethiopia Somali and Afar Regions and Borena Zone of Oromiya Region. London: ODI.

25. Population Reference Bureau. (2010). World population data sheet. Retrieved from http://www.prb.org/pdf10/10wpds eng.pdf 
26. Rayburn, E. (2007). Drought management before, during and after the drought. Wageningen, Netherlands: Wageningen Academic Publishers,

27. Republic Of Kenya, Ministry of state for special programmes. (2008). Review and Analysis of Existing Drought Risk Reduction Policies and Programmes in Kenya: National Report on Drought Risk Reduction Policies and Programmes.

28. Rohrbach D.D., Mashingaidze A.B. \& Mudhara M. 2005. Distribution of relief seed and fertilizer in Zimbabwe: Lessons from the 2003/04 season. Bulawayo: Zimbabwe. ICRISAT.

29. Roy, K. \& Hirway, I. (2007). Multiple impacts of drought and assessment of drought policy in major Drought prone states in India. Gujarat. Centre for development alternatives.

30. Samra, J.S., (2004), Review and analysis of drought monitoring, declaration and management in India, IWMI Working Paper 84. Colombo, Sri Lanka: International Water Management Institute.

31. Schilderinck, G. (2009). Drought Cycle Management in arid and semi-arid Kenya: A relevant disaster reduction model: An empirical study of Garissa, Marsabit, Samburu \& Wajir. Hague: CORDIAD.

32. Sen, A.K., (1981), Poverty and Famines: An Essay on Entitlements and Deprivation, Oxford: Clarendon Press.

33. Turnbull, M. (2010). REGLAP Policy baseline report: Reducing the vulnerability of pastoral communities through policy and practice change in the horn and East Africa: Final report. Nairobi: Oxfam.

34. UNDP. (2011). Mainstreaming Drought Risk Management: A primer. Nairobi, United Nations Office at Nairobi (UNON) Publishing Services Section.

35. UNISDR. (2009). Drought Risk Reduction Framework and Practices: Contributing to the Implementation of the Hyogo Framework for Action. Geneva, Switzerland: United Nations secretariat of the International Strategy for Disaster Reduction (UNISDR).

36. UNISDR. (2007). Drought Risk Reduction Frameworks and Practices: Contributing to the implementation of Hyogo framework for Action. Preliminary version, Geneva, Switzerland: UNISDR.

37. Zwaagstra, L., Sharif, Z., Wambile, A., De Leeuw, J., Said, M.Y., Johnson, N., Njuki, J., Ericksen, P. \& Herrero, M., (2010), An assessment of the response to the 2008-2009 drought in Kenya: A report to the European Union Delegation to the Republic of Kenya. Nairobi, Kenya: ILRI (International Livestock Research Institute). 